\title{
Desenvolvimento de uma Rede de Conhecimentos sobre Gênero Textual através da Rede Laifi
}

\author{
Juliane Quevedo Simonetto ${ }^{1}$, Giliane Bernardi ${ }^{1}$ \\ ${ }^{1}$ Programa de Pós-Graduação em Tecnologias Educacionais em Rede - Universidade \\ Federal de Santa Maria - (UFSM) - Santa Maria - RS - Brasil \\ jqsimonetto@yahoo.co.br, gilianedinf.ufsm.br
}

\begin{abstract}
Resumo. $O$ presente artigo propõe o desenvolvimento de uma rede de conhecimentos sobre gêneros textuais com alunos de Ensino Médio de uma escola da rede pública estadual. $O$ ensino de gêneros textuais nas aulas de Lingua Portuguesa é fundamental para o desenvolvimento da capacidade sociocomunicativa dos alunos. Nesse sentido, apresenta-se a alternativa de aliar o estudo desses gêneros e as redes sociais virtuais, principalmente, a Laifi nas práticas educacionais. Para tanto, são relatadas as atividades realizadas com duas turmas de primeiro ano. Como avaliação dessas atividades, foi aplicado um questionário System Usability Scale (SUS) aos estudantes, com o qual conseguimos perceber a concordância dos mesmos para a usabilidade da Rede Laifi.
\end{abstract}

Palavras-chave: gênero textual, rede social, Laifi

\begin{abstract}
This paper proposes the development of a knowledge network about textual genres with high school students of a public school. The teaching of textual genres in Portuguese classes is fundamental to the development of socio communicative ability in the students. In this sense, we present the alternative of joining the study of gender and social networks, especially the Laifi in educational practices. Therefore, we report the activities carried out with two first-year classes. As evaluation of these activities, was applied to students a System Usability Scale (SUS) questionnaire, with which we can perceive the agreement of the same to the usability of Laifi social network.
\end{abstract}

Keywords: textual genres; social network, Laifi

\section{Introdução}

As Orientações curriculares para o ensino médio - área de Linguagens, Códigos e suas Tecnologias (2006) direcionam o caminho a ser trilhado pelos docentes com o intuito de que, trabalhando com gêneros textuais, ocorra uma significativa contribuição com a formação integral dos discentes. Marcuschi (2010) afirma que os gêneros textuais são ações sociodiscursivas para agir e dizer sobre o mundo. Bezerra (2010) ratifica argumentando que, apesar de pouco praticado, o ensino da Língua Portuguesa deve ocorrer a partir da leitura, análise e produção de textos e, assim, desenvolvam-se competências linguísticas, textuais e comunicativas para que, deste modo, o jovem possa questionar e modificar o mundo letrado atual.

Nesta pesquisa são apresentadas experiências realizadas na disciplina de Língua Portuguesa com duas turmas de primeiro ano do ensino médio de escola da rede 
pública. As atividades ocorreram entre os meses de agosto e setembro de 2014, a partir da necessidade de inserção do conceito e produção do gênero textual crônica.

É importante ressaltar que essa escola organiza (com apoio de outras Instituições) e participa há trinta e cinco anos do Concurso Literário Municipal de Crônicas e Poesias. A motivação dos alunos a participar desse evento é elevada e faz com que toda a escola esteja envolvida para o sucesso do mesmo. Alguns projetos, ao longo do tempo, foram realizados paralelamente ao Concurso, entre eles as oficinas de leitura e produção textual. As avaliações feitas pelos professores, ao final do processo de cada Concurso Literário, mostraram a necessidade de trabalho mais efetivo com os gêneros textuais na sala de aula.

A iniciativa de desenvolver uma rede de conhecimentos através de uma rede social virtual parte dessa necessidade aliada ao uso de novas tecnologias, pois, conforme Kenski (2008), o ensino mediado pela tecnologia digital tem por princípio que todos somos seres sociais (professores e alunos) e aprendemos melhor de forma colaborativa, portanto, a participação de todos é indispensável.

Considerando essas questões, este artigo tem como objetivo apresentar o desenvolvimento de uma rede de conhecimentos sobre o gênero textual crônica, por meio da rede social Laifi, com o objetivo de trabalhar os conceitos associados a esse gênero.

\section{O Ensino de Gêneros Textuais}

As Orientações curriculares para o ensino médio - área de Linguagens, Códigos e suas Tecnologias (2006), elaboradas pelo Ministério da Educação (MEC) através da Secretaria de Educação Básica, trazem, como função da escola, a promoção de condições para que os alunos reflitam sobre o conhecimento construído e desenvolvam autonomia para serem cidadãos questionadores e transformadores na sociedade contemporânea. Somado a isso, afirmam que o ensino de Língua Portuguesa possui o papel de possibilitar letramentos múltiplos através do refinamento das habilidades de leitura e de escrita e a formação da capacidade de reflexão sobre a língua e a linguagem. Dessa forma, sendo a leitura e a escrita bases das relações de identidade e também de poder, percebe-se a importância do desenvolvimento de competências discursivas, fazendo com que o ensino de Língua Portuguesa tenha como princípio a valorização de diversas ideias e formas de expressão.

Para a concretização desse papel atribuído à Língua Portuguesa é imprescindível o trabalho com gêneros textuais, pois, conforme Marcuschi (2008), gêneros textuais são os textos que encontramos em nossa vida diária e que apresentam padrões sociocomunicativos característicos definidos por composições funcionais, objetivos enunciativos e estilos concretamente realizados na integração de forças históricas, sociais, institucionais e técnicas. Ainda percebemos no cotidiano da escola um ensino voltado ao aspecto formal e estrutural da língua e não como, segundo o autor, constituinte de propriedade sociocomunicativa em que se prezam as funções, intenções e interesses na abordagem realizada. Segundo Schneuwly e Dolz (1999), os gêneros textuais são a porta de entada para as práticas de linguagens. Conforme os autores, sendo a escola um espaço de comunicação, deve possibilitar o desenvolvimento de múltiplas capacidades de linguagem.

A compreensão de texto é muito valorizada e mais frequente que tantas outras atividades no ensino de Língua Portuguesa. Contudo, esse fato não remete ao êxito nos conceitos trabalhados, pois ainda predomina o trabalho apenas com conteúdos 
específicos. Os gêneros previstos para a prática de produção de textos escritos, entre outros, são: contos, poemas, notícia, editorial, carta do leitor e entrevista (Marcushi, 2008). Para Bezerra (2010), professores e alunos enfatizam mais a estrutura do texto, pois a escola sempre trabalhou relegando a função dos mesmos, tornando-os simples formulários a serem preenchidos. A autora ainda ressalta que o estudo de gêneros nas aulas de Língua Portuguesa pode levar a resultados profícuos por considerar seus usos e funções dentro de situações comunicativas, ou seja, os alunos construirão seus conhecimentos na interação com parceiros mais experientes.

Dias et al. (2012) afirmam que existe atualmente uma diversidade de exigências que aumentam a gama de práticas, gêneros e textos que devem ser tratados na sala de aula. Diante disso, os autores apontam que a capacidade de uso das ferramentas disponibilizadas pela tecnologia digital passa a estar intimamente ligada a competências que devem ser desenvolvidas pelos sujeitos contemporâneos. Assim, apresentamos como alternativa o uso de redes sociais como apoio à produção textual.

\section{Gêneros Textuais e Redes Sociais}

As redes sociais, associadas às ferramentas da Web 2.0, possibilitam uma nova forma de relacionamento, independente de tempo e espaço, as chamadas redes sociais na internet (Barcellos et al, 2012). Essas, normalmente, são utilizadas para postar e compartilhar fotos, comentários, vídeos e para fazer amigos, mas para potencialização do processo de ensino e aprendizagem são utilizadas de forma menos frequente.

Segundo Yates (2000), citado por Marcuschi (2010b), com as novas tecnologias digitais vem-se dando uma espécie de "radicalização do uso da escrita" e nossa sociedade parece tornar-se "textualizada", isto é, passar para o plano da escrita. Essa escrita, tende a ter uma linguagem informal e mais ágil respeitando o meio disponível. Assim, o instrumento tecnológico interfere na natureza do gênero produzido, pois esse amplia o conceito composicional de gênero como instrumento comunicativo. As formas emergentes de gênero são diversificadas e dinâmicas e caracterizam-se, diferentemente das formas não virtuais, por esse uso intenso da escrita. Cabe, nesse ponto, repensarmos a ligação entre escrita e oralidade na relação com os gêneros emergentes nas redes sociais da internet. Afinal, uma das características centrais dos gêneros em ambientes virtuais é a alta interatividade. Isso lhes dá um caráter inovador no contexto das relações entre fala-escrita (Marcuschi, 2010b). Nas redes sociais virtuais pode-se inserir diversos elementos nos textos, levando a uma interação entre escrita, imagem e som. Marcuschi (2010) ainda ressalta, para fins de caracterização do gênero, a permanência ou não do documento no tempo, ressaltando, para tanto, a recuperação dos textos produzidos nesses gêneros. Tendo em vista as tecnologias na sociedade contemporânea, é primordial ressaltar a necessidade de repensar, para o ensino de gêneros, conceitos como: linearidade, estrutura, coesão e coerência.

Diante do exposto, propõe-se o desenvolvimento de uma rede de conhecimento sobre gênero textual através da rede social Laifi, que será apresentada na próxima seção.

\subsection{A Rede Social Laifi}

A Laifi é uma rede social virtual criada pelo Grupo Virtuous, de Porto Alegre, em 2011, para que os usuários registrem suas histórias (chamadas de laifis) de forma inovadora e prática (Laifi, 2015). Hoje, a Laifi é utilizada também para explicar diversos assuntos de forma didática e gráfica. 
Nessa rede a informação pode e deve ser criada de forma cooperativa. Costa e Silva et al. (2012) abordam o potencial da aprendizagem cooperativa e afirma que essa é mais que uma simples estratégia para favorecer os processos de ensino e aprendizagem, pois o educador deve perceber o seu papel como mediador e o papel do aluno como sujeito da aprendizagem. Além disso, as atividades devem ser desafiadoras com o intuito de exercitar o pensamento crítico.

Segundo Kenski (2008), em uma abordagem cooperativa de ensino o aluno aumenta a autonomia, a responsabilidade e se expõe mais facilmente. Assim, o professor torna-se um mediador durante o processo e aprende junto com seus alunos. Conforme os criadores da rede (Laifi, 2015), alguns diferenciais do Laifi são:

- Colaboração: várias pessoas criam juntas um mesmo acontecimento;

- Abrangência: os laifis abordam qualquer assunto do mundo, seja pessoal (festas, eventos, viagens, etc) ou de interesse geral (esportes, televisão, filmes, etc);

- Didática: tudo é exposto de forma gráfica, cronológica e com mecanismo de ampliação (zoom), para melhor visualização dos conteúdos;

- Ambientação: ao navegar em um laifi, o usuário pode sentir-se "dentro" daquela história; e

- Historicidade: os acontecimentos ficam registrados como histórias e são colocados em uma linha do tempo para serem relembrados.

Além desses, destaca-se também a interatividade que, segundo Silva (2012), ocorre quando existe complexidade, multiplicidade, não linearidade, bidirecionalidade, potencialidade, imprevisibilidade, etc, aspectos esses que proporcionam ao usuário liberdade para participar, intervir e criar. Na próxima seção, serão apresentados alguns trabalhos correlatos relacionados ao uso de redes sociais na educação, bem como o uso da rede Laifi no cenário educacional.

\subsection{Trabalhos Correlatos}

É possível identificar alguns trabalhos voltados à análise de redes sociais virtuais como potencializadoras do processo de ensino e aprendizagem, mas ainda são em menor número os que relatam atividades com gênero textual e redes sociais virtuais.

O Facebook, seu uso e suas potencialidades, aparece na maioria das pesquisas atuais envolvendo redes sociais virtuais. Em pesquisa realizada por Canabarro e Basso (2013), 88\% dos professores consultados acreditam na possibilidade de utilização dessa rede social para estudos com seus colegas e $70 \%$ vêem alternativas para uso com os alunos. É citado o uso da ferramenta "grupos" para atividades a distância, para debates, feedback das aulas, agenda, entre outras. Conforme Tavares et al. (2013), em estudo sobre o uso complementar da rede social virtual Facebook nas atividades realizadas em salas de aula no ensino presencial, as inovações realizadas na mudança ou implementação da comunicação possibilitaram uma melhoria na aprendizagem dos alunos, principalmente, pela disponibilização de materiais adicionais às aulas.

Já Paula et al. (2012), consideram o Tumblr ${ }^{1}$ uma excelente ferramenta de apoio ao ensino da língua materna e ressaltam a interação entre professor-aluno ao usar essa rede. Essa conclusão surgiu através de pesquisa quantitativa, na qual foram aplicados

1 O tumblr é uma rede social em que o usuário possui sua página pessoal e, através dela, pode publicar e compartilhar texto, imagem, citação, links, chat, áudio e vídeo. 
dois questionários a alunos do ensino médio de Olinda (PE). Com base na análise do primeiro questionário, que teve como intuito identificar a melhor prática para inserir a rede social no processo pedagógico, foi realizada a escrita dos gêneros resenha e carta utilizando o Tumblr. Logo após, outro questionário foi aplicado com objetivo de analisar a eficiência da rede social como ferramenta de ensino. Além dos aspectos já mencionados, os autores relatam a importância do professor como orientador e motivador para o sucesso da proposta realizada.

Lopes et al. (2011) propõem atividade de escrita colaborativa de um microconto no Twitter, ao qual dão o nome de twitconto, com alunos de graduação. Para os autores, a conectividade e o modo de pensar e agir inseridos nas mídias digitais devem ser aproveitados para potencializar o processo de ensino e aprendizagem. Righi (2014) apresenta a rede Laifi como forma de organização e divulgação dos conhecimentos pesquisados em um estudo sobre brincadeiras antigas. $\mathrm{Na}$ escolha da rede social foi considerada sua importância e interesse junto aos alunos. Como resultados desse projeto, é destacado pela autora o envolvimento dos estudantes, trazendo uma maior motivação ao processo de ensino e aprendizagem.

Considerando os trabalhos apresentados, percebe-se que a utilização das redes sociais virtuais citadas, possivelmente, ocorra pela inserção das mesmas no cotidiano dos alunos promovendo sua motivação quando inseridas no trabalho pedagógico. A seguir, relata-se o desenvolvimento de uma rede de conhecimentos sobre gênero textual através da Rede Laifi.

\section{Rede Laifi sobre o Gênero Crônica: aspectos metodológicos e desenvolvimento}

Conforme descrito anteriormente, o objetivo principal deste trabalho foi analisar a utilização da Rede Laifi como apoio ao processo de ensino e aprendizagem do gênero textual crônica, sob o ponto de vista de usabilidade da própria ferramenta, bem como sob o ponto de vista da aprendizagem do conteúdo educacional. Para tanto, foram selecionadas duas turmas de primeiro ano do ensino médio. A turma A, com vinte e seis alunos, foi considerada a turma de controle e, por isso, não utilizou a Rede Laifi. A turma B, com vinte e três alunos, realizou as atividades propostas com apoio da Rede Laifi.

As atividades foram realizadas paralelamente com as turmas dentro da disciplina de Língua Portuguesa durante os meses de agosto e setembro de 2014. Inicialmente, a professora apresentou um mapa conceitual para tipos e gêneros textuais. Segundo Moreira (2010), mapas conceituais são diagramas indicando relações entre conceitos, ou entre palavras que usamos para representar conceitos com o propósito de procurar promover a aprendizagem significativa. Desta maneira, podem ser usados em todas as áreas do conhecimento, com finalidades instrucionais ou avaliativas. Ainda conforme o autor, é preciso que, primeiramente, o aluno perceba o significado de mapa conceitual, mas que esse nunca seja imposto como correto ou único.

Logo após, os estudantes leram a crônica intitulada "Tempo é ternura", de Fabrício Carpinejar (Carpinejar, 2013). Ao terminarem, iniciou-se uma conversa sobre o tema da crônica que, claramente, sensibilizou a maioria dos jovens. Além disso, alguns já iniciaram as conexões entre o texto e os conceitos gerais trazidos no mapa conceitual.

Optou-se pela realização de pré e pós-teste, ambos através da elaboração de mapas conceituais, sobre o gênero textual crônica. Salienta-se que neste artigo serão descritos apenas os resultados da avaliação de usabilidade da Rede Laifi, sendo que a análise dos mapas conceituais será apresentada em outro estudo. Assim, como pré-teste, 
no próximo encontro, foi solicitado que os alunos elaborassem um mapa conceitual para o gênero textual crônica, com a finalidade de que os estudantes, de ambas as turmas, pudessem expor seus conhecimentos prévios. Cabe ressaltar que a avaliação de mapas conceituais, como abordou Moreira (2010), é essencialmente qualitativa, pois o professor deverá buscar neles informações sobre os significados e relações entre conceitos-chave segundo o ponto de vista do aluno.

Ao término do pré-teste, somente com base nas atividades descritas até aqui, os alunos produziram, na sala de aula, suas crônicas com temática livre. Os textos foram recolhidos pela professora para leitura e apontamentos necessários.

A partir deste ponto, as turmas realizaram atividades distintas, mas ainda sincrônicas. A turma A (controle), dividida em seis grupos, pesquisou sobre o gênero textual crônica em seis livros didáticos disponibilizados pela biblioteca da escola durante cinco aulas. $\mathrm{O}$ resultado da pesquisa foi sistematizado pelos componentes do grupo no próprio caderno de aula.

A turma B (experimento) foi, primeiramente, apresentada à Rede Social Laifi e todos puderam tirar dúvidas e efetuar o cadastro na mesma. A seguir, no laboratório de informática da escola, foi iniciada a pesquisa sobre o gênero textual crônica. Para essa atividade, a turma foi dividida em seis grupos. A partir do resultado de suas pesquisas, cada grupo elaborou sua laifi dentro da referida rede, como está exemplificado na figura 1. As laifis, depois de prontas, ficaram liberadas para que toda a turma tivesse acesso. Para todo o trabalho, foram concedidas cinco aulas no laboratório de informática.

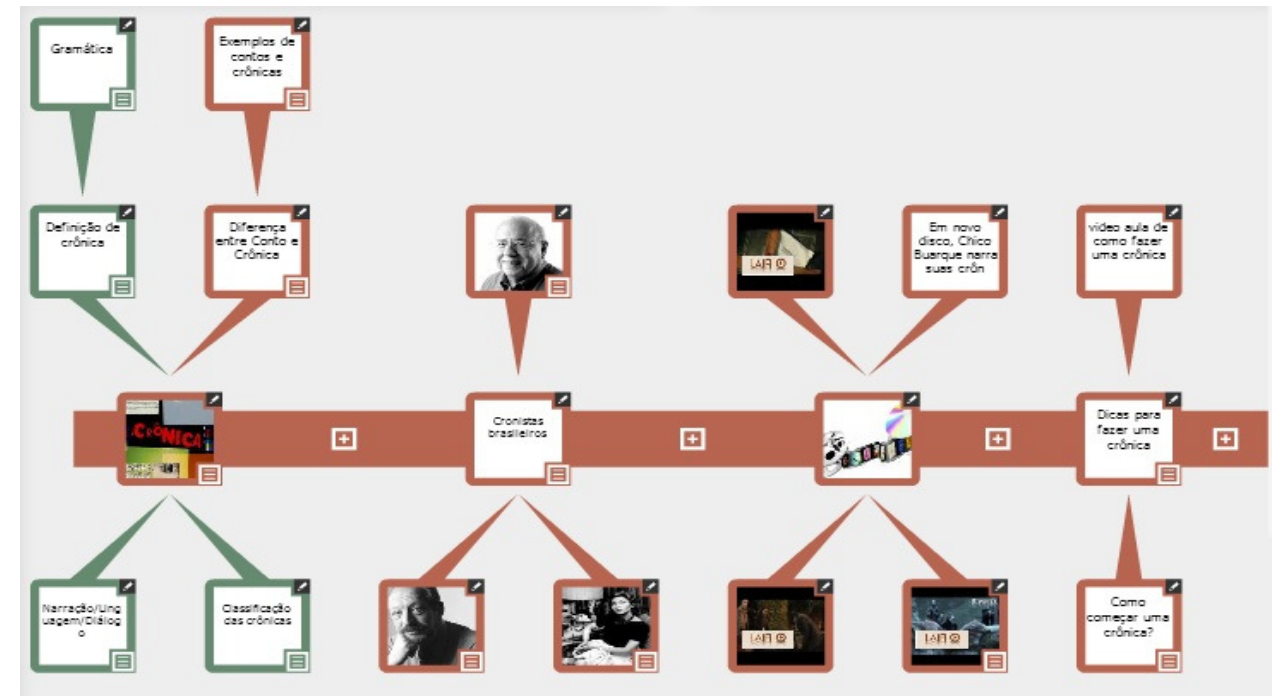

Figura 1 - Exemplo de laifi

A seguir, as duas turmas realizaram o pós-teste, através de um novo mapa conceitual sobre o gênero textual crônica, que não será detalhado neste artigo conforme já mencionado anteriormente. Após a conclusão dessas atividades, as duas turmas receberam os textos produzidos anteriormente e efetuaram a reescrita com base nos estudos realizados durante as aulas. A professora, outra vez, recolheu os textos para leitura e apontamentos. Finalmente, os estudantes fizeram a redação final de suas crônicas e puderam inscrevê-las no XXXV Concurso Literário Municipal - fase interna.

A turma que utilizou a Laifi participou de um teste de usabilidade para analisar de forma mais detalhada a própria rede social. Para tal, empregamos a escala de usabilidade System Usability Scale (SUS), a qual, segundo Brooke (1996), trata-se de uma escala composta por dez questões com uma perspectiva global de avaliações 
subjetivas. Utilizou-se a escala Likert (Likert, 1932) para avaliar a concordância ou discordância do usuário. Os usuários possuíam cinco alternativas de respostas e, cada uma, com o seu respectivo valor: Discordo Totalmente (1), Discordo Parcialmente (2), Indiferente (3), Concordo Parcialmente (4) e Concordo Totalmente (5).

Ao analisar as respostas, conforme Brooke (1996), é preciso realizar a subtração dos seguintes valores: nas questões de número ímpar, a pontuação é estabelecida através do valor informado na resposta do usuário, sendo subtraído a quantia de 1; já nas questões de número par, a pontuação é composta da quantia definida em 5 e subtraído o valor da resposta informada pelo usuário.

A soma de todas as pontuações das respostas do usuário é multiplicada por 2,5, para estimar o valor global do SUS. Esses são definidos de 0 a 100 e classificados em uma escala de sete adjetivos. Bangor et al. (2009) apresentam sete possibilidades com intervalos entre os valores, as quais podem ser atribuídas ao trabalho avaliado: Best Imaginable (Melhor Imaginável), Excellent (Excelente), Good (Bom), OK (Aceitável), Poor (Pobre), Awful (Horrível) e Worst Imaginable (Pior Imaginável). A próxima seção destaca os resultados obtidos.

\section{Avaliação e Análise dos Resultados}

Durante a realização das atividades, as turmas demonstraram grande interesse pelas propostas apresentadas. A escolha da crônica foi considerada adequada, pois, ao término da leitura, os alunos iniciaram um debate sobre o tema e lembraram de outros textos do autor.

$\mathrm{Na}$ atividade de pré-teste, as turmas demonstraram bastante interesse pela possibilidade de, utilizando mapas conceituais, relacionar conceitos novos com outros já internalizados. Fizeram, inicialmente, um rascunho das suas ideias para, logo após, elaborarem o seu mapa conceitual. Também perceberam que os mapas conceituais podem ser usados em todas as disciplinas e em várias ocasiões, entre eles: estudo de determinado conteúdo, apresentação de conceitos para o professor e para os colegas.

Ao produzirem a primeira versão de seus textos, a maioria dos alunos sentiu dificuldade, pois não tinha segurança se o conhecimento prévio que possuía estava totalmente adequado para a realização da proposta solicitada, ou seja, a escrita de uma crônica. Um aluno questionou se poderia ser um texto em versos, outro se crônica era uma "historinha". A turma permaneceu em silêncio, porém, alguns, ao final, solicitaram que os colegas lessem seus textos.

A análise dessa produção pela professora mostrou, realmente, que alguns alunos não conseguiram desenvolver o gênero textual crônica. As dificuldades mais presentes foram relativas à escolha do tema, estrutura e linguagem. A turma A (controle), ao iniciar a atividade de pesquisa nos livros didáticos, mostrou-se muito agitada, com conversas paralelas ao assunto que, em determinados momentos, atrapalharam o andamento da atividade. Ao longo do trabalho, os grupos tornaram-se mais organizados, comentavam as leituras realizadas, faziam anotações e sistematizavam os conceitos que acreditavam pertinentes para compreensão do gênero textual trabalhado. Mesmo assim, 
alguns alunos não se envolveram na atividade, pois consideraram a atividade enfadonha e, sendo assim, não colaboraram com o grupo em que estavam inseridos.

Já a turma B (experimento), desde a apresentação da Rede Laifi, demonstrou grande interesse em explorá-la. Os grupos trabalharam durante todos os períodos: selecionaram material (vídeos, charges, tirinhas, fotos, textos verbais) e discutiram sobre a organização da laifi do grupo. Como não conheciam a referida rede social virtual, os alunos ficaram muito motivados e trabalharam de forma colaborativa. Importante ressaltar, no que diz respeito ao envolvimento da turma, que todos os grupos realizaram inserções nas suas laifis fora do horário de aula.

A realização do pós-teste foi considerada muito importante na avaliação dos alunos, pois acreditavam ter mais clareza sobre o gênero textual crônica. Todos os alunos elaboraram o rascunho das ideias, antes de elaborar o mapa conceitual. Ao realizarem a reescrita do texto, os alunos logo perceberam os aspectos que precisavam ser melhorados. Alguns, inclusive, optaram por escrever uma nova crônica. Foram feitas relações da produção textual solicitada com os mapas conceituais elaborados. Um grande número de alunos, de ambas as turmas, participou do XXXV Concurso Literário Municipal. Uma aluna da turma B conquistou, por sua crônica, Menção Honrosa na fase interna do certame.

A turma que elaborou laifis sobre o gênero textual crônica participou de uma avaliação, através da escala de usabilidade System Usability Scale (SUS), para analisar de forma mais detalhada a própria rede social. Responderam ao questionário 20 dos 23 alunos que participaram do desenvolvimento. O valor global estimado do SUS, segundo as respostas dos usuários, foi 77,25. Esse resultado, demonstra que a Rede Social Laifi, dentro da classificação da escala de adjetivos, é considerada de boa usabilidade pelos usuários.

A partir da análise das respostas desse questionário, verifica-se que 54,5\% dos participantes gostariam de utilizar a Rede Laifi em outras iniciativas; $77 \%$ acham essa Rede fácil de ser manipulada; 63,6\% acreditam que não precisarão de auxílio técnico para manuseá-la e que todos podem aprender a usá-la muito rapidamente. Esses percentuais ratificam a ótima aceitação da turma às atividades propostas dentro da Rede Social Laifi e o grande potencial dessa ferramenta para o desenvolvimento de novas práticas de ensino. Ao serem questionados se sentiam-se confiantes ao usar a Laifi, $59,1 \%$ dos estudantes concordaram e 18,2\% mostraram-se indiferentes a essa questão. Acredita-se que, uma das razões para esse elevado índice de concordância, é a forma colaborativa de trabalho adotada em tal Rede e a autonomia gerada nos estudantes. A observação das respostas ainda indicou que alguns alunos, 22,7\%, perceberam algumas inconsistências na Rede Laifi. Essa questão nos remete ao fato de essa ainda não ser uma rede familiar a todos, pois é utilizada, principalmente, para fins educacionais. Tal questão, pode ser analisada futuramente quando os alunos terão mais acesso e, consequentemente, mais trabalhos produzidos dentro de tal Rede Social. 
Assim, após todos esses apontamentos, percebe-se que a Rede Laifi pode potencializar o ensino de gêneros textuais, pois promove o trabalho colaborativo, tornando o estudante protagonista do processo de ensino e aprendizagem.

\section{Considerações Finais}

Este artigo teve como objetivo principal propor o desenvolvimento de uma rede de conhecimentos sobre gênero textuais com alunos de ensino médio de uma escola da rede pública estadual. Após as atividades propostas dentro desta pesquisa, constata-se que o caminho a ser percorrido ainda é longo, porém o olhar do professor deve focar no trabalho com os mais diversos gêneros textuais, pois é a possibilidade que os alunos possuem de trabalhar com a língua em suas mais diferentes formas e, principalmente, com pensamento reflexivo e ações críticas. Nesse sentido, a utilização da Rede Laifi contribuiu de forma significativa no processo de ensino e aprendizagem do gênero textual crônica, pois os alunos trabalharam de forma autônoma e colaborativa.

Como trabalho futuro, apresenta-se como primordial a análise dos mapas conceituais realizados pelos alunos durante o pré-teste e o pós-teste sobre o gênero textual crônica, bem como a relação dos mesmos com a produção realizada.

\section{Referências Bibliográficas}

BANGOR, A.; KORTUM, P.; MILLER, J. Determining What Individual SUS Scores Mean: adding an adjective rating scale. Jounal of Usability Studies (JUS), [S.1.], v.4, n.3, p.114-123, 2009.

BARCELLOS, G.T.; PASSERINO, L.M.; BEHAR, P.A. Redes sociais e comunidades: definções, classificações e relações. RENOTE - Revista Novas Tecnologias na Educação, Porto Alegre, CINTED-UFRGS, v. 8, n.2, jul. 2010. ISSN: 1679-1916.

BEZERRA, M.A. Ensino de língua portuguesa e contextos teóricos-metodológicos. In: DIONÍSIO, A.P.; MACHADO, A.R.; BEZERRA, M.A.(Org.). Gêneros textuais \& ensino. São Paulo: Parábola Editorial, 2010. p.39-49.

BOHN, C.S.; DANDOLINI, G.A.; SOUZA, J.A; ALVES, J.B.M. Redes sociais: uma interpretação do ciberspaço. RENOTE - Revista Novas Tecnologias na Educação, Porto Alegre, CINTED-UFRGS, v.9, n.2, dez.2011.

BROOKE, J. SUS - A quick and dirty usability scale. In: P. W. Jordan, B. Thomas, B. A. Weerdmeester, . A. L. M. (Ed.). Usability evaluation in industry. [S.1.]: London: Taylor \& Francis, 1996. p.189-194.

CANABARRO, M.M.; BASSO, L.O. Os professores e as Redes Sociais - é possível utilizar o Facebook para além do "curtir"? RENOTE - Revista Novas Tecnologias na Educação, Porto Alegre, CINTED-UFRGS, v.11, n.1, jul. 2013.

CARPINEJAR, F. Tempo é ternura. Zero Hora, Porto Alegre, p.2, 21 jun.2011. Disponível em:<http://carpinejar.blogspot.com.br/2011/06/tempo-e-ternura.html>. Acesso em: 28 jul.2014.

COSTA E SILVA, A.P.; MACHADO, M.J.; FERREIRA, S.M.B. Interação, cooperação e sistematização da aprendizagem em ambiente virtual: uma proposta metodológica 
inovadora. RENOTE - Revista Novas Tecnologias na Educação, Porto Alegre, CINTED-UFRGS, v.10, n.1, jul.2012.

DIAS, A.V.M.; MORAIS, C.G.; PIMENTA, V.R.; SILVA, W.B. Minicontos multimodais: reescrevendo imagens cotidianas. In: ROJO, R.; MOURA, E. Multiletramentos na escola. São Paulo: Parábola, 2012. p. 75-94.

KENSKI, V. Novos processos de interação e comunicação no ensino mediado pelas tecnologias. Cadernos de Pedagogia Universitária, São Paulo, USP, n.7, nov.2008.

LAIFI. Sobre o Laifi. Disponível em< http://www.laifi.com/about.php>. Acesso em: 15 abr. 2015.

LIKERT, R.A. TECHNIQUE FOR THE MEASUREREMENT OF ATTIUDES. Archives of Psychology, [S.1.], v.22, n.140, p.1-55, 1932.

LOPES, T.R.C.; ALVES, I.M.R. Novos meios, novas práticas de ensino-apredizagem: proposta de produção colaborativa de um twiconto. RENOTE - Revista Novas Tecnologias na Educação, Porto Alegre, CINTED-UFRGS, v.9, n.2, dez.2011.

MARCUSCHI, L.A. Gêneros textuais: definição e funcionalidade. In: DIONÍSIO, A.P.; MACHADO, A.R.; BEZERRA, M.A.(Orgs.). Gêneros textuais \& ensino. São Paulo: Parábola Editorial, 2010. p.19-38.

MARCUSCHI, L.A. Gêneros textuais emergentes no contexto da tecnologia digital. In: MARCUSCHI, L.A.; XAVIER, A.C. (Orgs.). Hipertexto e gêneros digitais: novas formas de construção de sentido. São Paulo: Cortez, 2010. p.15-80.

MARCUSCHI, L.A. Produção textual, análise de gêneros e compreensão. São Paulo: Parábola Editorial, 2008.

MINISTÉRIO DA EDUCAÇÃO. Orientações curriculares para o ensino médio. Brasília, 2006. 239p.

MOREIRA, M.A. Mapas conceituais e aprendizagem significativa. São Paulo: Centauro, 2010. 80 p.

PAULA, D.F.O. de; CAMELO, M.B. Redes Sociais: o tumblr e suas práticas escolares. RENOTE - Revista Novas Tecnologias na Educação, Porto Alegre, CINTEDUFRGS, v.10, n.1, jul.2012.

RIGUI, M. M. T. Uso da Rede Social Laifi no resgate das brincadeiras antigas. Santa Maria: Universidade Federal de Santa Maria - UFSM, RS, 2014. Monografia de Especialização em Mídias Aplicadas à Educação.

SCHÄFER, P.B.; FAGUNDES, L.C; PRIMO, A.F.T.; CAÑAS, A.J. Desenvolvimento da conceituação sobre a escrita mediado pela construção de mapas conceituais em uma rede de comunicação online: alguns resultados. RENOTE - Revista Novas Tecnologias na Educação, Porto Alegre, CINTED-UFRGS, v.10, n.3, dez.2012.

SCHNEUWLY, B.; DOLZ, J.. Os gêneros escolares: das práticas de linguagem aos objetos de ensino. Revista Brasileira de Educação, n.11, mai-jun-jul-ago. 1999.

SILVA, M. Sala de aula interativa. São Paulo: Edições Loyola, 2012. 270 p.

TAVARES, W.; PAULA, H.C. de; PAULA, A.P.P. de. Comunicação e interação no ensino através do uso de redes sociais virtuais. RENOTE - Revista Novas Tecnologias na Educação, Porto Alegre, CINTED-UFRGS, v.11, n.3, dez. 2013. 